\title{
The effect of substrate on the production of infectious virus by cells in culture*
}

\author{
James Varani, $\dagger \S$ Matthew J. Bendelow and \\ William J. Hillegas $\ddagger$
}

\begin{abstract}
Herpes simplex virus type I (HSV-1), infectious bovine rhinotracheitis virus (IBR) and turkey herpesvirus were examined for growth in cells cultured on three different substrates. The substrates were glass, DEAE-dextran and collagen gel. With two of the viruses, HSV-1 and IBR, there were no apparent differences in production as a function of substrate. In contrast, the amount of the turkey herpesvirus which was recovered varied greatly with the substrate. Titers were highest on glass, followed by DEAE-dextran and then collagen gel. Our previous studies have indicated that the substrate on which anchorage-dependent cells are grown in vitro has an affect on a number of biological and biochemical properties. The present study indicates that the production of commercially important biologicals can be affected by the substrate.
\end{abstract}

\section{INTRODUCTION}

The large-scale in vitro cultivation of anchorage-dependent mammalian cells is done using a variety of technologies. ${ }^{1-7}$ While glass or polystyrene plastic is generally used as the substrate in conventional monolayer cultures or roller bottles, a number of different materials have been used in some of the other technologies. In addition to glass and polystyrene plastic, these materials include collagens of various types and in a number of different formulations, highly-charged molecules such as DEAE-dextran, porous

* Received for publication 22 April 1988.

$\dagger$ Department of Pathology, The University of Michigan Medical School, 1301 Catherine Road, Ann Arbor, MI 48109, USA.

¥ Solohill Engineering, Inc., Ann Arbor, MI 48104, USA.

$\S$ To whom correspondence should be sent. 
silica, acrylamide, liquid fluorocarbons and alginate. ${ }^{1,7,8-11}$ While each of these different materials will support the growth of anchorage-dependent cells, it has recently come to be appreciated that the properties expressed by the cells are influenced to a significant degree by the substrate on which they are grown. Changes in the material used as the substrate may lead to an alternation in growth rate, saturation density, cell-substrate adhesion and morphology. ${ }^{11,12}$ Substrate-dependent differences in the production of proteolytic enzymes and metabolites of arachidonic acid have also been observed. ${ }^{13,14}$ The present study extends our work on the influence of the substrate on cell behavior. In the present studies, we have examined the production of viruses by cells grown on a number of different substrates. The results indicate that production of some, but not all, viruses is affected by the substrate on which the cells are cultivated. In using anchorage-dependent cells in culture for the production of biologicals, possible effects of the substrate on production of the desired product need to be taken into account.

\section{MATERIALS AND METHODS}

\section{Cells}

The cells used in these experiments include MRC-5 human diploid fibroblasts, primary chick embryo cells and Madin-Darby bovine kidney (MDBK) cells. Each of these cell types is an important substrate for the production of viral vaccines for human or veterinary use. The MRC-5 human fibroblasts were obtained from Flow Laboratories (McLean, VA), maintained in monolayer culture and used through passage 35 . The chick embryo cells were prepared from 10-day fertilized hens' eggs and used in primary culture. The MDBK cells were kindly provided by David Buell (Grand Laboratories; Larchwood, IO). All of the cells were maintained on the minimal essential medium of Eagle with Earle's salts (MEM) supplemented with $10 \%$ fetal bovine serum, $100 \mathrm{U} / \mathrm{ml}$ of penicillin, $100 \mu \mathrm{g} / \mathrm{ml}$ of streptomycin and $0.25 \mu \mathrm{g} / \mathrm{ml}$ of fungizone. Growth was at $37^{\circ} \mathrm{C}$ with $5 \% \mathrm{CO}_{2}$. Prior to use and during the course of these studies, the MRC- 5 and MDBK cells were examined for mycoplasma contamination by growth in mycoplasma broth and on mycoplasma agar. They were always shown to be frec of contamination by these criteria.

\section{Microcarriers}

Three different, commercially-available microcarriers were used in these studies. These included microcarriers made from DEAE-Dextran (Cytodex I) obtained from Pharmacia (Piscataway, NJ); collagen gel microcarriers (Ventregel) obtained from Ventrex Laboratories, Inc. (Portland, ME); and glass-coated microcarriers (Biosil) obtained from Solohill Engineering (Ann Arbor, MI). Each of the three types of microcarrier was prepared for use according to the recommendations of the respective manufacturers.

\section{Microcarrier cultures}

The experiments were carried out in $200 \mathrm{ml}$ suspension microcarrier cultures as described in a recent report. ${ }^{11}$ The amount of each microcarrier used was chosen to provide comparable surface areas. For Cytodex I and Ventregel this was $1 \mathrm{~g} /$ culture. For Biosil beads, $5 \mathrm{~g} /$ culture were used. The cultures were established on day zero using 
$1 \times 10^{8}$ MRC-5 fibroblasts, $1 \times 10^{9}$ chick embryo cells and $1 \times 10^{8} \mathrm{MDBK}$ cells as inoculum. One day later, the number of viable cells per culture was determined using a nuclei assay. ${ }^{15}$ Appropriate amounts of each virus were added to the cultures at this rime.

\section{Virus studies}

Herpes simplex virus type I (HSV-1, strain MacIntyre; ATCC VR-538), infectious bovine rhinotracheitis virus (IBR; ATCC VR-864) and turkey herpesvirus (ATCC VR-584B) were obtained from the American Type Culture Collection. Stocks of each virus were propagated in vitro. HSV-1 was grown in MRC-5 cells and frozen as a cell-free stock in liquid nitrogen. IBR virus was grown in MDBK cells and frozen as a cell-free stock in liquid nitrogen. The turkey herpesvirus was grown in chick embryo cells. Virus-infected cells were frozen in liquid nitrogen as viable cells. Titers of the virus stocks were determined using the appropriate cell types as indicators. Plaque assays were used with HSV-1 and IBR; an infectious center assay was used with the turkey herpesvirus. To examine virus growth in cells on the various substrates, the cells were grown in $200 \mathrm{ml}$ cultures as described above. Virus (either cell-free HSV-1 or IBR or virus-infected chick embryo cells for turkey herpesvirus) was added to the cultures one day later. On each of the following days, samples were taken from each culture and frozen for virus titration. HSV-1 and IBR were frozen as cell-free virus while turkey herpesvirus-infected chick embryo cells were frozen as viable cells. Virus assays were done in exactly the same manner as with stock virus.

\section{RESULTS AND DISCUSSION}

The three cell types used in this study showed differences from one another in their response to the different substrates. MDBK grew well on all three of the substrates and a high percentage of the cells could be harvested in a viable state with proteolytic enzymes. Chick embryo cells grew well on glass but less well on the other two substrates. In particular, these cells did not adapt well to collagen gel. MRC-5 cells were like MDBK cells in that they proliferated equally well on all three substrates. However, MRC- 5 cells were resistant to removal from DEAE-dextran with proteolytic enzymes. As a result, the viability of the harvested cells was lower than the viability of the cells harvested from glass. These findings were described in a recent report. ${ }^{14}$

In light of the above results, it was of interest to determine if production of virus would also be affected by the substrate on which the cells were grown. Production of three different types of virus was examined. As shown in the left-hand panel of Fig. 1, comparable amounts of infectious HSV-1 were obtained from MRC-5 cells grown on either glass, collagen gel or DEAE-dextran. The high level of $\mathrm{HSV}-1$ recovered from MRC- 5 cells grown on DEAE-dextran is consistent with the fact that this virus is shed in high titer into the culture medium and does not require the cells to be removed in a viable state from the substrate. In contrast, the turkey herpesvirus is strongly cell-associated. Therefore, it might be expected that production of this virus would be inhibited in cells grown on DEAE-dextran. This is, in fact, what was observed. The number of infectious centers (viable, virus-infected cells) recovered from cultures of chick embryo cells grown on DEAE-dextran was much lower than the number recovered from cultures of the same cells grown on glass (Fig. 1, middle panel). The number of infectious centers recovered from the cells grown on collagen gel was also 
low, reflecting the fact that chick embryo cells did not grow well on this substrate. IBR virus was the third virus examined (Fig. 1, right-hand panel). As was expected (since there were no apparent substrate-dependent differences in MDBK cell growth on the three substrates $\left.{ }^{14}\right)$, virus production occurred equally well on all three substrates.
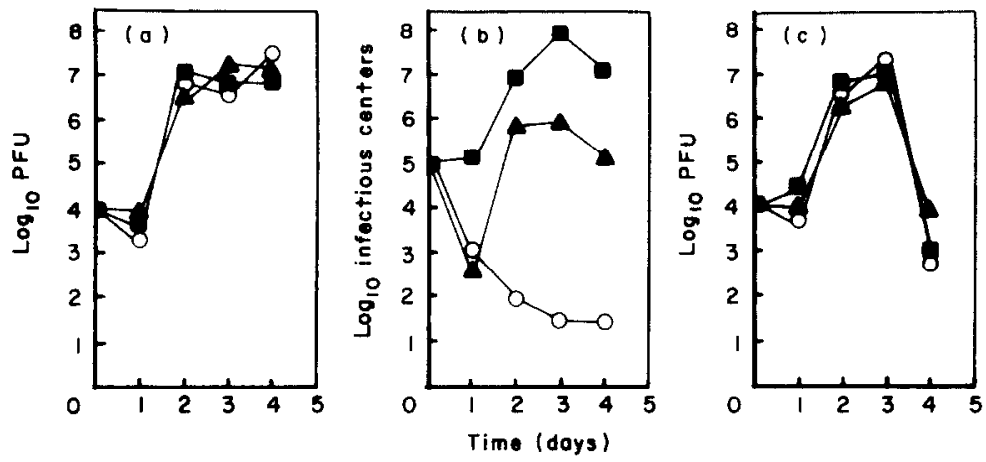

Fig. 1 Virus production by cells grown on three different substrates: glass ( $\boldsymbol{\square})$; DEAE-dextran ( $\boldsymbol{\Delta}$ ); and collagen gel (O). (a) HSV production: MRC-5 human diploid fibroblasts were infected with $4 \log _{10}$ plaque-forming units (PFU) per culture (approximately $1 \times 10^{8}$ cells in $200 \mathrm{ml}$ ) and incubated at $37^{\circ} \mathrm{C}$. On subsequent days, the cultures were harvested and examined for infectious virus using a plaque assay in MRC-5 cells. (b) Production of turkey herpesvirus; chick embryo cells were inoculated with 5 Log 10 virus-infected fibroblasts per culture (approximately $5 \times 10^{8}$ cells in $200 \mathrm{ml}$ ) and incubated at $37^{\circ} \mathrm{C}$. On subsequent days, the cultures were harvested and examined for numbers of virus-infected cells using an infectious centcr assay in chick embryo cells. (c) IBR production: Madin-Darby bovine kidney cells were infected with $4 \log _{10}$ plaque-forming units per culture (approximately $1 \times 10^{8}$ cells in $200 \mathrm{ml}$ ) and incubated at $37^{\circ} \mathrm{C}$. On subsequent days, the cultures were harvested and examined for infectious virus using a plaque assay in Madin-Darby bovine kidney cells.

The results demonstrate that the production of some, though not all, viruses by cells in culture is strongly influenced by the substrate on which the cells are grown. This has practical implications. There are now a number of different materials available for use as substrates in the in vitro cultivation of cells. ${ }^{1,7-11}$ As newer technologies replace conventional monolayer culture and roller bottles for some industrial applications, substrate materials other than plastic or glass may be used. In the light of the present data it is not unreasonable to expect that quantitative and/or qualitative differences in the production of useful biologicals will result from the alterations in substrate materials. The potential for such differences must be taken into account in considering new technologies for in vitro cell cultivation.

At present, we do not understand the biochemical basis for the differences reported here. In previous studies it has been shown that cells grown on different substrates produce widely differing amounts of proteolytic enzymes ${ }^{12,13}$ Human fibroblasts grown on DEAE-dextran produced greater amounts of plasminogen-dependent fibrinolytic activity than the same cells grown on a number of other substrates. Substantial amounts of both urokinase-type plasminogen activator (u-PA) and tissue-type plasminogen activator ( $t-P A)$ were found in the culture fluids of the cells grown on DEAE-dextran. In contrast, only u-PA was found in the culture fluid of the same cells grown on glass. Substrate-dependent differences in production of arachidonic acid metabolites have also been noted. ${ }^{14}$ Human fibroblasts grown on a number of substrates (other than glass) 
produced variable amounts of different cyclooxygenase metabolites but no detectable lipoxygenase products. When the same cells were cultured on glass, they produced smaller amounts of cyclooxygenase metabolites but also produced detectable amounts of lipoxygenase products including leukotriene $B_{4}$ and leukotriene $C_{4}$. The significance of these findings as they relate to the present observations are not yet known. However, both proteolytic enzymes and metabolites of arachidonic acid serve to regulate a variety of cellular functions. ${ }^{16-21}$ It would not be surprising to find that substrate-dependent differences in the production of these metabolites are associated with differences in growth characteristics.

\section{Acknowledgement}

This study was supported in part by grant CA43353 from the USPHS

\section{REFERENCES}

1. Giard DJ, Thilly WG, Wang DIC, Levine DW. Virus production with a newly developed microcarrier system. Appl Environ Micro 1977; 34: 668-672.

2. Liebhaber H, Pajot T, Riordan JT. Growth of high titered Rubella virus in roller bottle cultures of Vero cells. Proc Soc Exp Biol Med 1969; 130: 12-14.

3. Fenters JD, Fordyce PA, Gerin JL, Holper JC. Propagation of Rhinovirus on WI- 38 cell monolayers in rolling bottles. Appl Microbiol 1967; 15: 1460-1466.

4. House W, Shearer M, Maroudas NG. Method for bulk culture of animal cells on plastic film. Exp Cell Res 1972: 71: 293-296.

5. Spier RE, Whiteside JP. The production of foot-and-mouth disease virus from BHK $21 \mathrm{C}$ 13 cells grown on the surface of DEAE Sephadex A50 beads. Biotechnol Bioeng 1967; 18: 659-667.

6. Griffith JB, Thornton B, McEntee I. The development and use of microcarrier and glass sphere culture techniques for the production of herpes simplex viruses. Dev Biol Stand 1982; 50: $103-110$.

7. Van Wezel AL. (1967) Growth of cell strains and primary cells on micro-carriers. Nature 1967; 216: 65-66.

8. Gebb C, Clark JM, Hirtenstein MD, Lindgren G, Lindskog U, Lundgren B, Vretblad P. Alternative surfaces for microcarrier culture of animal cells. Dev Biol Stand 1982; 50: 93-102.

9. Kesse C, Giaever I. Cell growth on liquid microcarriers. Science 1983; 219: 1448-1449.

10. Nielson V, Johansson A. Biosilon; optimal culture conditions and various research scale culture techniques. Dev Biol Stand 1980; 46: 131-136.

11. Varani J, Dame M, Beals TF, Wass JA. Growth of three established cell lines on glass microcarriers. Biotech Bioeng 1983; 25: 1359-1372.

12. Varani J, Dame M, Rediske J, Beals TF, Hillegas W. Substrate-dependent differences in growth and biological properties of fibroblasts and epithelial cells grown in microcarrier culture. J Biol Stand 1985; 13: 67-76.

13. Varani J, Hasday JD, Sitrin RS, Brubaker PG, Hillegas WA. Proteolytic enzymes and arachidonic acid metabolites produced by MRC-5 cells on various microcarrier substrates. In Vitro Cell Develop Biol 1986; 22: 575-582.

14. Varani J, Bendelow MJ, Chun JH, Hillegas WA. Cell growth on microcarriers: comparison of proliferation on and recovery from various substrates. J Biol Stand 1986; 14: $331-336$

15. Sanford K, Earle W, Evans V. The measurement of proliferation in tissue cultures by enumeration of cell nuclei. J Nat Cancer Inst 1950; 11: 773-794. 
16. Hynes RO. Role of surface alterations in cell transformation: The importance of proteases and serum proteins. Cell 1974; 1: 147-156.

17. Burger MM. Proteolytic enzymes initiating cell division and escape from contact inhibition of growth. Nature 1970; 227: 170-171.

18. Chen LB, Buchanan JM. Mitogenic activity of blood components. I. Thrombin and prothrombin. Proc Natl Acad Sci USA 1976; 72: 131-135.

19. Goodwin JS, Webb DR. Regulation of the immune response by prostaglandins. Clin Immunol Immunopathol 1980; 15: 106-113.

20. Goldman DW, Goetzl EJ. Mediation and modulation of immediate hypersensitivity and inflammation by products of the oxygenation of arachidonic acid. In: Ward PA, ed. Immunology of Inflammation: Handbook of Inflammation. Elsevier, Amsterdam 1983; 4 : $163-187$.

21. Jimenez de Asua L, Clingan LD, Rudland PS. Initiation of cell proliferation in cultured mouse fibroblasts by prostaglandin F2 $\alpha$. Proc Natl Acad Sci USA 1975; 72: 2724-2728. 